\title{
The Effect of Environmental Taxes on Steady-State Consumption
}

\author{
Bidisha Lahiri \\ Department of Economics and Legal Studies, Oklahoma State University, Stillwater, USA \\ Email: bidisha.lahiri@okstate.edu
}

Received 19 October 2014; revised 28 November 2014; accepted 12 December 2014

Copyright (C) 2014 by author and Scientific Research Publishing Inc.

This work is licensed under the Creative Commons Attribution International License (CC BY). http://creativecommons.org/licenses/by/4.0/

(c) (i) Open Access

\begin{abstract}
This paper examines the effects of environmental taxes on the demand and supply sides of the economy and uncovers two opposite forces on long-term production. An increase in the environmental tax stimulates abatement behavior as producers lower production from the same capital stock but simultaneously lower per-unit emissions increases consumers' demand for the cleaner goods hence increasing the capital stock. Starting from a low level of environmental taxes, my model finds that initially the demand-driven positive relationship dominates while at a higher level of environmental taxes, the production lowering negative effect dominates; the transition occurs before the economy reaches the optimal tax rate.
\end{abstract}

\section{Keywords}

Environmental Tax, Steady State, Production, Emission

\section{Introduction}

It is commonly recognized that a higher pollution tax lowers the marginal productivity of resources and has a negative effect on long-term production. However, there exists a specialized segment of the literature recognizing that stricter abatement policies could also have some positive effects. A tighter environmental policy can potentially operate through different mechanisms such as investment, education, R\&D, productivity improvement of inputs, etc., to influence the long-term growth rate. Thus the final effect of these two forces determines whether the net effect of a stricter environmental policy is to increase or decrease long-term production levels. Examples of some articles exploring the positive effects of higher pollution taxes are as follows. Bovenberg and Smulders [1] [2] show that a higher pollution tax improves the quality of the environment, which increases productivity and hence has a positive effect on production in the long term. Ono [3] determines that a higher pollution tax leads to a higher quality of environmental capital bequeathed to future generations, which is equiv- 
alent to greater environmental wealth. For future generations, this is equivalent to the positive income effect of a high pollution tax in the long run. Grimaud and Rouge [4] assume that emissions generated during production have a negative effect on welfare. Using an endogenous growth model, they find that a carbon tax has a negative impact on short-term production and consumption but has a positive impact on long-term growth.

In a slightly different approach, Gupta and Ray Burman [5] consider the allocation of government income tax revenue across abatement expenditures and productive public expenditures. In their model, a higher share of abatement expenditures improve the efficiency of productive public expenditures, generating the positive effect of pollution control. Acemoglu et al. [6] consider the effect of environmental policies toward endogenous technology. When stricter environmental policies encourage technological innovation, a positive effect on production emerges.

This theoretical literature shows that a stricter environmental policy is not incompatible with a positive effect on economic production; however, in showing this result, the studies rely on strong assumptions that may appear to favor such results. In the current paper, I uncover the positive (and negative) effects of stricter environmental policies in a simple model that is not based on a priori assumptions regarding the positive effect of the policies. Instead, the model derives its results based on the observation that for consumers the trade-off between consumption and environmental quality is such that richer consumers prefer lower pollution while poorer consumers are more accepting of higher pollution if that affords them marginally more consumption. This results in a negative relationship between consumption and pollution. On the resource constraint side, a positive relationship exists between pollution and production. Introducing a change in environmental taxes in the setting of these positive and negative relationships between production and pollution generates very interesting comparative statics results.

The rest of the paper is stet-up as follows. I set-up the model in Section 2 where I first elaborate the production conditions which coupled with the resource constraint underlies the negative relation between environmental taxes and consumption. Next I develop the demand side of the model that leads to the positive relation between environmental taxes and consumption. Finally I put together the demand and supply dimensions to characterize the steady state equilibrium. The effects of changes in environmental taxes are explored as comparative statics for the steady state equilibriums. Finally Section 3 concludes with a summary of the current findings and directions for future research.

\section{Model}

To capture the final effect of an environmental policy on long-term equilibrium (steady-state) output, I will focus on how emission taxes affect both supply and demand within the economy. I introduce emissions and environmental taxes in the Neoclassical Growth Model with an endogenous savings rate developed by Ramsey [7], Cass [8] and Koopmans [9]. The price of the produced commodity $Y_{t}$ is normalized to one; return to capital $\left(r_{t}\right)$, environmental taxes $\left(\tau_{t}\right)$, and the value of marginal disutility from pollution $\left(P_{z, t}\right)$ are all expressed relative to this normalized price ${ }^{1}$.

\subsection{Supply}

Production $\left(Y_{t}\right)$ is a decreasing function of capital $\left(K_{t}\right)$ and emits pollution $\left(Z_{t}\right)$ as a byproduct. In the absence of any abatement activity, production and emissions are given by Equation (1).

$$
Y_{t}=\left(K_{t}\right)^{s_{y}}, \quad Z_{t}=K_{t} \quad \text { where } \quad s_{y} \leq 1
$$

Emissions can be abated if some resources are diverted for this purpose. Following the approach popularized by Copeland and Taylor [10], the production of output and of the emission byproduct are combined into a single function using abatement technology. If $\theta_{Y_{t}}$ is the fraction of resources spent for abatement activity in sector $Y_{t}$, then the output level after abatement activity is:

$$
Y_{t}=\left\{K_{t}\left(1-\theta_{Y_{t}}\right)\right\}^{s_{y}} \text {. }
$$

The emission level after abatement activity is:

${ }^{1}$ Although the output, capital, emission, and welfare variables are presented in levels, they are open to percapita interpretation. 


$$
Z_{t}=\left(1-\theta_{Y_{t}}\right)^{1 / \alpha^{\prime}} K_{t}
$$

Here $\alpha^{\prime}$ is the parameter from abatement technology in the $Y$ sector. Combining (2) and (3) by eliminating $\theta_{Y_{t}}$ between the above two production functions results in the Cobb-Douglas form of production relationship.

$$
Y_{t}=Z_{t}^{\alpha} K_{t}^{s_{y}-\alpha} \text { where } \alpha=\alpha^{\prime} * s_{y}
$$

Emissions appear as an input for production; higher emissions are associated with a higher production level, implying that fewer resources are diverted for abatement of the pollution.

Suppose that the government imposes a tax $\tau_{t}$ on per-unit emissions. Profit maximizing producers will engage in abatement activity until the level where the marginal product of the last unit of emission equals the cost of the emission tax:

$$
\tau_{t}=\alpha Y_{t} / Z_{t}
$$

Using this condition to eliminate emission level $Z_{t}$ from production function (4) expresses production $Y_{t}$ as a function of capital stock and the prevailing emission tax rates as in (5).

$$
Y_{t}=\left(\frac{\alpha}{\tau_{t}}\right)^{\frac{\alpha}{1-\alpha}}\left(K_{t}\right)^{\frac{s_{y}-\alpha}{1-\alpha}} \quad \text { i.e., } \quad Y_{t}=Y_{t}\left(K_{t} ; \alpha, s_{y}, \tau_{t}\right)
$$

I assume that emission tax revenues collected by the government are distributed back in a lump-sum manner so that they do not affect the national budget constraint. The only role of the emission tax is to ensure abatement activity by producers. Under optimal taxation where the tax level is set equal to consumers' disutility from emissions, the optimal tax ensures that the marginal cost to producers of emission reduction equals consumers' valuation of the marginal disutility from emissions.

\subsection{Resource Constraint}

Next I turn to the resource constraint of the economy that matches demand and supply. The total quantity produced every period $\left(Y_{t}\right)$ is used for consumption $\left(C_{t}\right)$ and capital $\left(K_{t}\right)$ accumulation purposes.

$$
\left(K_{t+1}-K_{t}\right)+C_{t}=Y_{t}
$$

Using (5) to represent production in the above resource constraint, I rewrite it as Equation (6).

$$
\left(K_{t+1}-K_{t}\right)+C_{t}=\left(K_{t}\right)^{\frac{s_{y}-\alpha}{1-\alpha}}\left(\frac{\alpha}{\tau}\right)^{\frac{\alpha}{1-\alpha}}
$$

\subsection{Demand}

On the demand side, I assume an infinitely lived consumer whose life-time welfare is the discounted sum of every period's welfare:

$$
U_{t}=\sum_{t=0}^{\infty} \rho^{t} u_{t}=\sum_{t=0}^{\infty} \rho^{t}\left[\ln \left(C_{t}\right)-\gamma \cdot Z_{t}\right]
$$

In any given period, the consumer derives positive but decreasing marginal utility from consumption and disutility from emissions ${ }^{2}$. If $P_{Z_{t}}$ is the marginal valuation of pollution while the price of the produced commodity is normalized to 1 as mentioned earlier, then Equation (8) shows that although the marginal disutility of emissions is assumed to be constant, pollution disutility is valued more strongly as economies get richer ${ }^{3}$.

\footnotetext{
${ }^{2}$ Copeland and Taylor (1997), “A Simple Model of Trade, Capital Mobility and the Environment,” NBER Working Paper 5898.

${ }^{3}$ As the valuation of pollution disutility becomes larger as $P_{t} C_{t}$ increases even with a constant $\gamma$, no further insight is gained by making $\gamma$ itself a function of $P_{t} C_{t}$.
} 


$$
\frac{P_{Z_{t}}}{1}=\frac{-\partial u_{t} / \partial Z_{t}}{\partial u_{t} / \partial C_{t}}, \quad \text { or } \quad P_{Z_{t}}=\gamma C_{t}
$$

Equation (9) is the Euler equation that embodies the first-order condition for maximizing intertemporal welfare (7) with respect to $K_{t+1}$ subject to resource constraint (6).

$$
\frac{1}{C_{t}}=\rho\left[\frac{1}{C_{t+1}}\left\{1+Y_{t+1}^{\prime}\left(K_{t+1}\right)\right\}-\gamma Z_{t+1}^{\prime}\left(K_{t+1}\right)\right]
$$

\subsection{Steady State}

The steady-state versions of resource constraint (6) and consumption Euler Equation (9)-presented as Equations (10) and (11), respectively-together determine steady-state equilibrium. At the steady state, the aggregate capital stock remains constant, as shown in Equation (10).

$$
\left(K_{t+1}-K_{t}\right)=0 \rightarrow C_{t}=\left(K_{t}\right)^{\frac{s_{y}-\alpha}{1-\alpha}}\left(\frac{\alpha}{\tau}\right)^{\frac{\alpha}{1-\alpha}} \text {, or } \bar{K}=\left[\bar{C}\left(\frac{\tau}{\alpha}\right)^{\frac{\alpha}{1-\alpha}}\right]^{\frac{1-\alpha}{s_{y}-\alpha}}
$$

Equation (11) below, derived from Equation (9), is the constant consumption equation. Consumption attains a steady level when the welfare cost of delaying consumption by one period equals the next period return from current investment. In this model with environmental externality, the next period return from investment requires that the emission disutility associated with additional capital in the next period be subtracted from the marginal productivity of capital. Equation (11) is the corresponding zero consumption growth equation.

$$
C_{t+1}-C_{t}=0 \rightarrow\left(\frac{1}{\rho}-1\right)=Y_{t+1}^{\prime}\left(K_{t+1}\right)-\left(\gamma C_{t+1}\right) Z_{t+1}^{\prime}\left(K_{t+1}\right) \text { or } \bar{K}=\left[\frac{\frac{s_{y}-\alpha}{1-\alpha}\left(\frac{\alpha}{\tau}\right)^{\frac{\alpha}{1-\alpha}}\left\{1-\gamma \bar{C}\left(\frac{\alpha}{\tau}\right)\right\}}{\frac{1}{\rho}-1}\right]^{\frac{1-\alpha}{1-s_{y}}}
$$

In standard growth models with no environmental externality, the return from investment is the marginal product of capital without necessitating the deduction of the disutility of emissions. Hence the steady-state consumption locus is a constant capital stock line in standard models; in the current model with emission disutility, it is a negatively sloped relationship between capital stock and consumption, as captured by Equation (11). If $K_{t}$ is interpreted in percapita units, then the assumption of the growth of labor implies growth of the aggregate capital stock; the same applies for characterizing steady-state consumption. The various parameters used in the equations of the model are tabulated in Table 1.

\subsection{Comparative Statics of an Emission Tax Change}

On the steady-state locus for resource constraint (10), steady-state consumption demand equals its production or supply. A higher environmental tax $\tau_{2}$ leads to greater abatement expenditures and hence lower production from any given stock of capital. Hence a stricter environmental policy pulls the steady-state capital locus to the left, as shown in Figure 1.

Table 1. Parameter interpretations and values.

\begin{tabular}{cl}
\hline Parameter & Explanation \\
\hline$s_{y}$ & Degree of returns to scale for $Y$ production $\left(s_{y} \leq 1\right)$ \\
$\alpha$ & Pollution emission coefficient for $Y$ production $\left(\alpha<s_{y}\right)$ \\
$\gamma$ & Pollution disutility parameter $(\gamma<1)$ \\
$\rho$ & Intertemporal discount rate $(\rho<1)$ \\
\hline
\end{tabular}




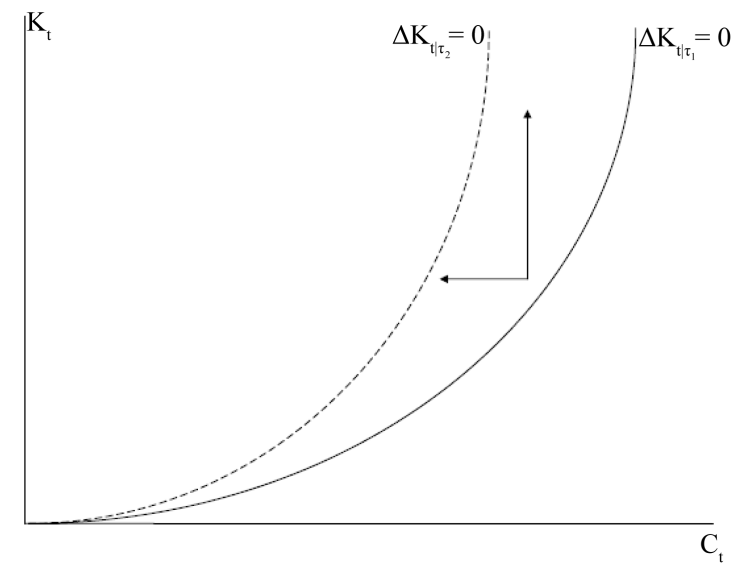

Figure 1. Effect of higher environmental tax on steady state capital locus.

In the steady-state version of consumption Euler Equation (11), the welfare cost of delaying consumption by one period $\frac{1}{\rho}-1$ equals the next period return from current investment. At relatively high levels of consumption, the marginal valuation of emission disutility is significant. Hence the above equality can be achieved either by a smaller capital stock accompanied by a relatively lax environmental tax $\tau_{1}$ (point $\mathrm{A}$ in Figure 2), or by a higher capital stock accompanied by a relatively strict environmental tax $\tau_{2}$ (point B in Figure 2). Points to the left of the intersection denote relatively low consumption resulting in relatively low marginal valuation of emission disutility. This segment is dominated by the marginal product reducing effects of a higher environmental tax on capital. This necessitates a smaller steady-state capital stock corresponding to higher environmental taxation to satisfy (11).

To see the long-term effect of an increase in environmental taxes, I look at the simultaneous effect of the shifts of both loci in Figure 3 .

While Figure 3 suggests that the change in the equilibrium could be in either direction, the solution emerging from solving equations (10) and (11) provides an interesting analytical result ${ }^{4}$.

$$
\hat{C} / \hat{\tau}=\left[\frac{\alpha\left(s_{y} \gamma C-\tau\right)}{\alpha \gamma C\left(s_{y}-\alpha\right)+(\tau-\alpha \gamma C)\left(1-s_{y}\right)}\right] \begin{cases}<0 & \text { if } \tau>s_{y} \gamma C \\ >0 & \text { if } \alpha \gamma C<\tau<s_{y} \gamma C \\ >0 & \text { if } \tau<\alpha \gamma C \text { as } s_{y} \rightarrow 1\end{cases}
$$

The tightening of environmental standards has two opposite effects. On one hand, it makes production associated with each unit of capital cleaner, so a higher capital stock becomes acceptable from the consumers' perspective. On the other hand, a higher environmental tax lowers the marginal product of capital, lowering production. In equilibrium, the resource constraint identifies an equilibrium where the positive and negative forces balance each other. The derivative $\mathrm{d} C / \mathrm{d} \tau$ is positive for lower values of $\tau$. Starting at relatively low pollution regulation levels, the positive effect on capital outweighs the negative effect, i.e., an increasing environmental tax raises steady-state capital, production, and consumption. This happens because a higher emission tax makes higher capital stock acceptable, and the positive effect on production and consumption is stronger than the negative effect of the lower marginal product of each unit of this higher capital stock. The response of consumption and production to increases in environmental taxation turns negative when $\tau=s_{y} \gamma C$. Raising taxes beyond this level results in higher capital stocks' positive effect on production and consumption being dominated by the negative marginal product impact.

The optimal emission tax is defined as the shadow cost of emissions to producers that equals the marginal disutility to consumers $\tau_{t}=P_{z, t}=\gamma C_{t}^{5}$. The incentive to raise steady-state consumption and production by raising the emission tax is not sufficient to drive the environmental tax to the optimal level; the relationship be-

\footnotetext{
${ }^{4}$ Derivation in Appendix.

${ }^{5}$ Refer to Equation (8).
} 


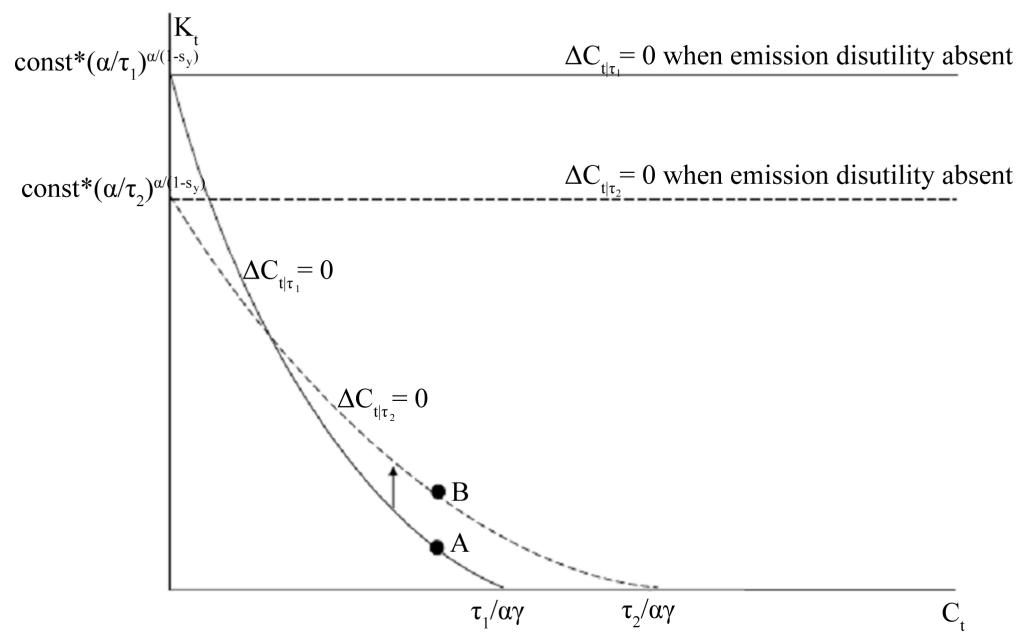

Figure 2. Effect of higher environmental tax on steady state consumption locus.

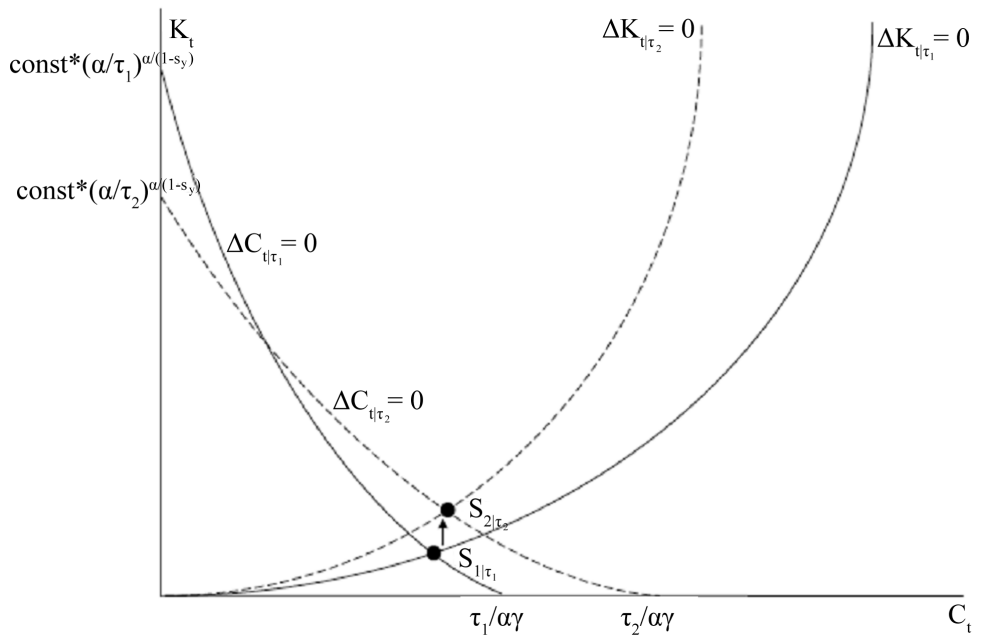

Figure 3. Effect of higher environmental tax on steady state equilibrium.

tween production and the environmental tax turns negative before environmental taxes reach the optimal level except in the case of constant returns to scale $\left(s_{y}=1\right)$.

\section{Conclusions and Future Directions}

While the production-lowering effects of stricter environmental policies remain the mainstream result, this paper contributes to the segment of literature that seeks to investigate the positive effects of higher emission taxes on long-term income and consumption. Instead of adding special characteristics to the model, this model uncovers the interaction of the positive and negative relationships between environmental taxes and consumption arising from basic demand and supply relationships. The role of the emission tax is to ensure abatement activity by the producers. Stricter environmental policy lowers supply from any given capital stock, but simultaneously the tighter policy increases demand for the cleaner good and hence increases the capital stock raising production and consumption. I consider the above forces at the steady state and uncover the transitional level of environmental tax where the relationship between environmental policy strictness and consumption turns from positive to negative. This switch happens before the attainment of the optimal environmental tax, defined as the level of taxation that equals consumers' valuation of pollution disutility. Hence the incentive to raise environmental taxes in order to increase steady state consumption is not sufficient to induce policymakers to set the environmental tax as high as the socially optimal level. 
There are some aspects that need to be addressed in future work. For example, the environmental quality addressed in this paper is a flow variable while many environmental quality variables are stock variables. Second, the international aspect both in terms of international spillovers of environmental externalities and international outsourcing of production are real-world complexities that need to be addressed in future extensions of this model.

\section{References}

[1] Bovenberg, A.L. and Smulders, S. (1995) Environmental Quality and Pollution Augmenting Technological Change in a Two Sector Endogenous Growth Model. Journal of Public Economics, 57, 369-391. http://dx.doi.org/10.1016/0047-2727(95)80002-Q

[2] Bovenberg, A.L. and Smulders, S. (1996) Transitional Impacts of Environmental Policy in an Endogenous Growth Model. International Economic Review, 37, 861-893. http://dx.doi.org/10.2307/2527315

[3] Ono, T. (2003) Environmental Tax Policy and Long Run Economic Growth. Japanese Economic Review, 54, $203-217$. http://dx.doi.org/10.1111/1468-5876.00254

[4] Grimaud, A. and Rouge, L. (2014) Carbon Sequestration, Economic Policies and Growth. Resource and Energy Economics, 36, 307-331. http://dx.doi.org/10.1016/j.reseneeco.2013.12.004

[5] Gupta, M.R. and Ray Barman, T. (2009) Fiscal Policies, Environmental Pollution and Economic Growth. Economic Modelling, 26, 1018-1028. http://dx.doi.org/10.1016/j.econmod.2009.03.010

[6] Acemoglu, D., Aghion, P., Bursztyn, L. and Hemous, D. (2012) The Environment and Directed Technological Change. American Economic Review, 102, 131-166. http://dx.doi.org/10.1257/aer.102.1.131

[7] Ramsey, F. (1928) A Mathematical Theory of Saving. Economic Journal, 38, 543-559. http://dx.doi.org/10.2307/2224098

[8] Cass, D. (1965) Optimum Growth in an Aggregative Model of Capital Accumulation. Review of Economic Studies, 32, 233-240. http://dx.doi.org/10.2307/2295827

[9] Koopmans, T.C. (1965) On the Concept of Optimal Economic Growth. Econometric Approach to Development Planning, North-Holland Publishing Company, Amsterdam, 225-287.

[10] Copeland, B.R. and Taylor, M.S. (1997) A Simple Model of Trade, Capital Mobility and the Environment. NBER Working Paper 5898. 


\section{Appendix: Effect of Higher Environmental Tax on Steady State Consumption}

Solve for steady-state consumption using Equations (10) and (11):

$$
\begin{aligned}
& {\left[\frac{\frac{s_{y}-\alpha}{1-\alpha}\left(\frac{\alpha}{\tau}\right)^{\frac{\alpha}{1-\alpha}}\left\{1-\gamma C\left(\frac{\alpha}{\tau}\right)\right\}}{\frac{1}{\rho}-1}\right]^{\frac{1-\alpha}{1-s_{y}}}=\left[C\left(\frac{\tau}{\alpha}\right)^{\frac{\alpha}{1-\alpha}}\right]^{\frac{1-\alpha}{s_{y}-\alpha}}} \\
& \frac{1-\alpha}{1-s_{y}} \ln \left[\left(\frac{1}{\tau}\right)^{\frac{1}{1-\alpha}}\{\tau-\alpha \gamma C\}+\frac{1-\alpha}{1-s_{y}} \ln \left[\alpha^{\frac{1}{1-\alpha}}\right]=\frac{1-\alpha}{s_{y}-\alpha} \ln \left[C\left(\frac{\tau}{\alpha}\right)^{\frac{\alpha}{1-\alpha}}\right]+\ln \left(\frac{1}{\rho}-1\right)\right. \\
& \frac{1-\alpha}{1-s_{y}} \ln \{\tau-\alpha \gamma C\}-\frac{1-\alpha}{1-s_{y}} \ln (\tau)^{\frac{1}{1-\alpha}}=\frac{1-\alpha}{s_{y}-\alpha} \ln (C)+\frac{1-\alpha}{s_{y}-\alpha} \ln (\tau)^{\frac{\alpha}{1-\alpha}}+\text { const } \\
& \frac{1-\alpha}{1-s_{y}} \ln \{\tau-\alpha \gamma C\}-\frac{1}{1-s_{y}} \ln (\tau)=\frac{1-\alpha}{s_{y}-\alpha} \ln (C)+\frac{\alpha}{s_{y}-\alpha} \ln (\tau)+\text { const }
\end{aligned}
$$

Total differentiation of the above equation to see the effect of a change in environmental taxes on steady state consumption:

$$
\begin{aligned}
& \frac{1-\alpha}{1-s_{y}}\left\{\hat{\tau} \frac{\tau}{\tau-\alpha \gamma P C}-\hat{C} \frac{\alpha \gamma C}{\tau-\alpha \gamma C}\right\}-\frac{1}{1-s_{y}} \hat{\tau}=\frac{1-\alpha}{s_{y}-\alpha} \hat{C}+\frac{\alpha}{s_{y}-\alpha} \hat{\tau} \\
& {\left[\frac{1-\alpha}{1-s_{y}} \frac{\tau}{\tau-\alpha \gamma C}-\frac{1}{1-s_{y}}-\frac{\alpha}{s_{y}-\alpha}\right] \hat{\tau}=\left[\frac{1-\alpha}{1-s_{y}}\left\{\frac{\alpha \gamma C}{\tau-\alpha \gamma C}\right\}+\frac{1-\alpha}{s_{y}-\alpha}\right] \hat{C}} \\
& \hat{C} / \hat{\tau}=\left[\frac{1-\alpha}{1-s_{y}} \frac{\tau}{\tau-\alpha \gamma C}-\frac{1}{1-s_{y}}-\frac{\alpha}{s_{y}-\alpha}\right] /\left[\frac{1-\alpha}{1-s_{y}}\left\{\frac{\alpha \gamma C}{\tau-\alpha \gamma C}\right\}+\frac{1-\alpha}{s_{y}-\alpha}\right] \\
& \hat{C} / \hat{\tau}=\left[\frac{\alpha\left(s_{y} \gamma C-\tau\right)}{\alpha \gamma C\left(s_{y}-\alpha\right)+(\tau-\alpha \gamma C)\left(1-s_{y}\right)}\right]
\end{aligned}
$$


Scientific Research Publishing (SCIRP) is one of the largest Open Access journal publishers. It is currently publishing more than 200 open access, online, peer-reviewed journals covering a wide range of academic disciplines. SCIRP serves the worldwide academic communities and contributes to the progress and application of science with its publication.

Other selected journals from SCIRP are listed as below. Submit your manuscript to us via either submit@scirp.org or Online Submission Portal.
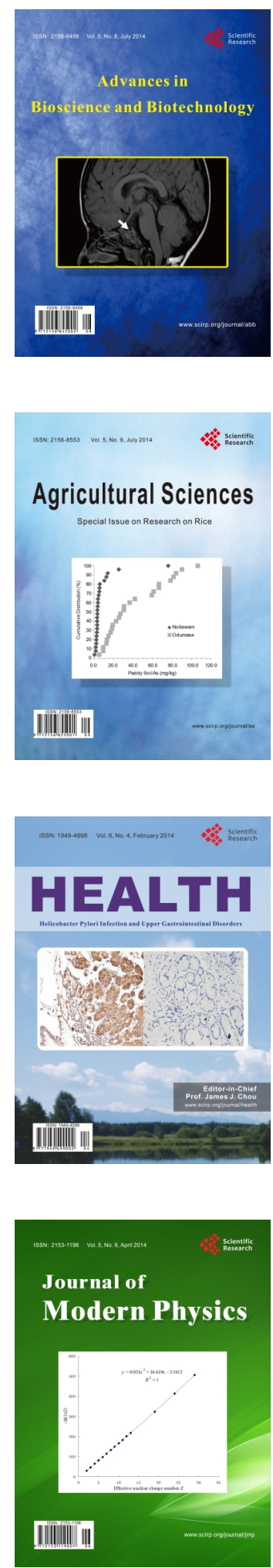
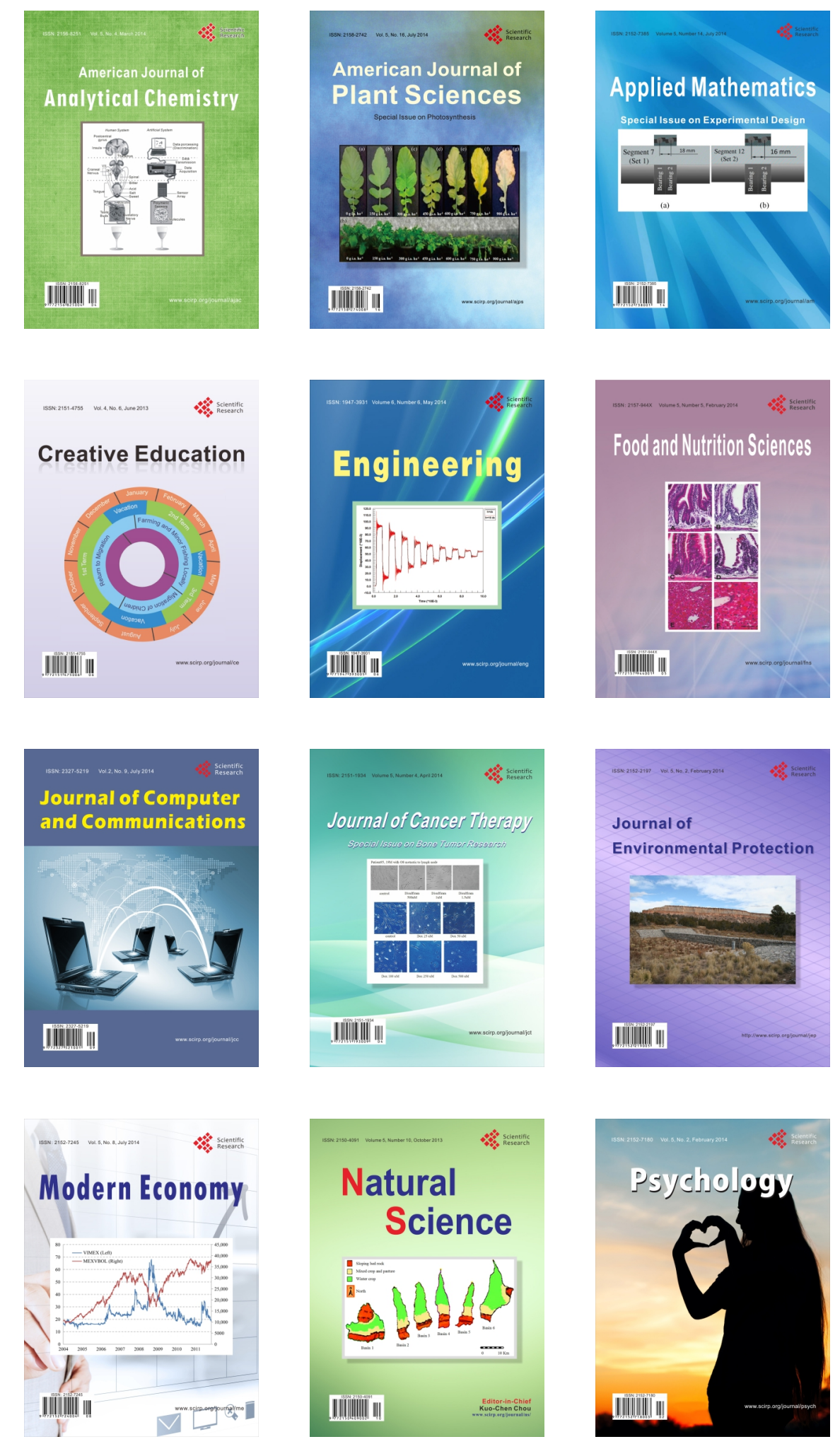